\title{
Monitoring DSI and Lancaster Indices for Study Dust and Sand Storm In Meteorological Mehrabad Station of Tehran
}

\author{
Rahman Sharifi $^{1 *}$ (D) , Mohammad. Khosroshahi ${ }^{2}$ (D) , Mehdi. Sadeghipourmarvi ${ }^{3}$ \\ ${ }^{1}$ Soil Conservation and Watershed Management Department, Agricultural and Natural Resources Research and Education \\ Center of Tehran Province, AREEO, Tehran, Iran \\ 2 Desert Research Department, Research Institute of Forests and Raneland, AREEO, Tehran, Iran. \\ ${ }^{3}$ Soil Conservation and Watershed Management Department, Agricultural and Natural Resources Research and Education \\ Center of Tehran Province, AREEO, Tehran, Iran
}

r.sharifi@Areeo.ac.ir

Received May 2021

Received in revised: June 2021

Published: June 2021

\begin{abstract}
ABSTRA CT
The first climatic factors affecting the phenomenon of dust and fine dust are collected, reconstructed, extended and completed in the form of DSI (Dust Storm Index) and Lancaster in Mehrabad meteorological station of Tehran was studied and analyzed. The results showed that in Mehrabad meteorological station in terms of temperature in 1992 the lowest value and in 1998, 2001, 2017 the highest value and in terms of humidity in 2017 the lowest amount of humidity and in 2000 the highest amount of humidity and in terms of rainfall in the year 2013 the lowest amount of precipitation and in 2019 the highest amount of precipitation and in terms of evaporation in 2009 the lowest amount of evaporation and in 1391 the highest amount of evaporation and finally in terms of number of dust days in 1998 the lowest number of days and in 2009 the highest number of days Dust has been recorded. Mehrabad station of Tehran in years showed DSI index, more than one number and Lancaster index, more than fifty number in most of the mentioned years, the values of temperature and evaporation are high and the values of precipitation and humidity are relatively low, which shows the direct relationship between the dust storm index (DSI index) and mobility index of sand dunes (Lancaster index) is almost too high and above the number It is noteworthy that in most of the mentioned years, Meteorological factors and data have been at Mehrabad station in Tehran.
\end{abstract}

Keywords: Dust-Climatic factors -Drought index -Desert - Dust and Sand Storm -Tehran

C2021 The Authors. Published by Fundamental Journals. This is an open-access article under the CC BY-NC

https://creativecommons.org/licenses/by-nc/4.0/

\section{INTRODUCTION}

The prediction of scientists suggests that in the future, the more temperate and rainfall earth will go to certain events. The average level of sea level will rise and many arid and semi-arid regions will be drier. The equilibrium of sensitive and fragile ecosystems on earth will emerge as a major challenge by climate change and climate volatility (Pelletier et al., 2015). One of the fundamental challenges that now face arid and desert areas is the dust-dust phenomenon. This phenomenon, although arises and arises in the desert regions, also affects the effects of other areas. On the other hand, the rainfall is an essential element for the development or adjustment of dust 
particles because surface moisture, vegetation, slight cold processes, and the like in one region are affected by rainfall. Even small quantities of soil moisture limit wind erosion.

It was assumed that dust production in semi-arid regions (with average rainfall at around $200-100 \mathrm{~mm}$ ) due to the slight cold processes of rocks and the production and concentration of micro-river deposits and the mixed of this surface deposit for agricultural activities is greater than that of dry or dry regions. Whereas, most recent research suggests that the strongest source of dust production on Earth is a Bodeleh pit with an average annual precipitation of less than $10 \mathrm{~mm}$. droughts must play a major role in increasing dust production. The correlation between the activity of dust and drought and drought for Africa (Prospero, Blades, Mathison, \& Naidu, 2005), Australia and the United States have proven. The seasonal distribution of precipitation is as important in prediction of dust production. In the Mojaveh Desert, California has its maximum annual precipitation in April and May, where wind speeds are high occurred when the total annual precipitation is significantly lower than normal precipitation. In addition to weather conditions, the surface factors (ground), plant cover and seasonal pattern are important in controlling dust development. Rangeland vegitation is more than $16 \%$ showing wind erosion (Sweeney, McDonald, \& Etyemezian, 2011).

Therefore, strengthening of rangeland vegetation causes stability of the surface and thus reducing wind and dust erosion. Surface roughness plants increase surface and thus reduce the wind velocity; the root system keeps the soil particles close together, increasing the soil moisture temporarily, thus stabilizing the surface area and the soil. Dunes and sand zones have occupied a third of the area of dry regions in low and middle latitudes and very important sights and ecosystems. They are a geomorphology and sedimental environment that responds to changes and climate variation across temporal and spatial scales (Lancaster, 2013).

Since the transit of sand is not measured as part of meteorological observations, such as other factors, there is no comparable data to examine the relation between the dust and the weather variables. However, there are other sources and data that can be used to assess the response of sand dunes and transmit them to climate change and variation. Typically, formation or activation of sand dunes are more evident in their dry periods, resulting in an increase in the deposition and activity of the sand in case of availability or sand mobility. Recent studies, however, show that this simplification of complex relationships is usually non-linear between the activity of sand dunes and climate (Clarke \& Rendell, 1998).

\section{DUST IN THE WORLD}

In general, there have been many researches in the world from the past to date with different views and purposes to research about origin, nature, characteristics, displacement paths, existing combinations of dust or dust, effects and consequences of their spread over cities and villages. In fact, deserts and land lakes, which have been transformed to small deserts due to regional climatic changes, are among the most active dust-producing sources. These regions usually have less annual precipitation than 288 to $258 \mathrm{~mm}$ and topography is situated in an area of topography. Dust is one of the most important environmental problems in the world that has attracted much attention in recent years. this problem affects all aspects of human life (including human health, influence on the industries of electricity distribution, the development of desertification, agriculture and ecotourism, etc.).

For sustainable management of dust, it has to be done at first and then review all comprehensive management. Internal or external sourcing of dust is important because the necessity of investing within the region or outside of the region will be considered as investor, and comprehensive management will also be emphasized that in the absence of attention to all aspects affecting the origin of dust of sustainable management will not be achieved and therefore all measures have been carried out. the purpose of this study was the study of the system from different aspects such as pedology, geology and meteorology in this regard. As an example of desert in Africa, the largest source of dust in the world is the dust that takes 155 million tons of dust annually. The main sources of this phenomenon in Sahara include Bodeleh pit, western Mali, southern Algeria and eastern Mauritania (Kermani, 2010).

More than $78 \%$ of the dust storms are attributed to the storm that come from the Horn of Africa (Prospero \& Lamb, 2003). The study of storms in the country of Mongolia showed that the most frequent occurrence of these storm is in the west of Mongolia, which is affected by the Gabi desert and the Great Lakes of Mongolia. Most of these types of hurricanes occur in the spring, where air and soil are dry (Natsagdorj, Jugder, \& Chung, 2003). Another studies, about the country's dust storms, is shown to be the cause of the storm, which has operated in northern China, and has been the pressure gradient between the northern China and the Gabi deserts and sand, the south and west of Mongolia (Liu, Jiang, Zheng, Kang, \& Qi, 2004).

According to the study of the Desert (Sahra) has a huge role in the production of global dust, in northwest Africa. Western China and parts of Mongolia are considered the second major source of desert dust (Esmaeili.O, 2005). Middle Eastern storms are mainly divided into a different kind of north, front, and convective forms. The main types of these storm are the northern type that takes place on Iraq, Kuwait and the Arabian Peninsula (Lashkari \& Keykhosravi, 2008). in recent years, dust storm in the middle east and especially in the Saudi Arabia and Iraq have caused significant damage to our country, ranging from its range to major cities. Analysis of flows and investigations of satellite imagery of the Middle East region shows that the world's sandy desert, called " Rub ' al - Khali, is one of the sources of dust phenomena in the Middle East region, which has been established in Saudi Arabia, Yemen, Oman and the United Arab Emirates (Esmaeili.O, 2005).

Dust storms in Iran, the southeast of Iraq and Syria, the Gulf and southern Saudi Arabia are the most frequent in the summer. The storms in the west of Iraq and Syria, Jordan, Lebanon, northern Saudi Arabia and southern Egypt are mostly in the spring. Whereas in southern Israel and the areas of northern Egypt occur in spring and winter (Furman \& Environment, 2003). According to a study of dust storms in the middle east, Iran, Sudan, Iraq, Saudi Arabia and all Gulf 
states in the first place indicate that the frequency of hurricanes in these regions indicates the fact that the frequency of hurricanes in these countries during the hot period of the year is higher than the rest of the periods (Furman \& Environment, 2003).

\section{DUST IN THE IRAN}

Therefore, it is important that management of the sourcing of dust or internal or external carriers will not be the same. the source of dust in the country is categorized in two phases of source of dust, internal dust, and source of dust or external dust. The main source of dust or external dust in the west and south of Iran is the location of the Euphrates and Euphrates rivers to the Euphrates and the Euphrates (north and northeast of Syria). As the origin of dust or internal dust in Razavi Khorasan province is increased from the north to the south (i.e., dust in the region from the Sistan and Baluchestan region). the results showed that the three important zones of dust in the south west of the country, including the west of Ilam and the border with Iraq, meet the southern borders of Ilam, northern Khozestan and Iraq and the surrounding areas of Horolazim Pond (Rezaeei.M, 2014).

Satellite images showed have at least a large portion of the dust march Khozestan in the local ponds of the source especially Horolazim pond. The high concentration of dust in Ahvaz, a figure of about one hundredth of $\mathrm{g} / \mathrm{m} 3$, which recorded a historical record, also indicates the proximity of the dust storm or the recent dust.

\section{MATERIAL AND METHODS}

In the beginning to prepare the weather data of Mehrabad station, in Tehran, the required action to collect a 30 - year statistical period was conducted. to cover the time of statistical data based on WMO (World Meteorological Organization) method, the meteorological data of the reconstruction, were completed. In the next step, data analysis can be noted that, usually, factors such as shifting the measurement location, change of time measurement, replacement of measurement time, replacement of devices and extreme local climate change may result in the heterogeneity in the data, which can be interpreted as a method of double crime curve and through numerical methods to sequence test. In the present study, the annual data homogeneity analysis of the stations was done using sequence test and completed data inhomogeneity.

After reconstruction and completion of statistical gaps, the relationship and annual and seasonal trends between the number of days associated with hurricanes And dust and the studied parameters are examined, in this section the days associated with dust as a dependent variable during the study period with simultaneous data of temperature, evaporation and precipitation and Other required and involved parameters in this phenomenon are compared as independent variables. The results of this part of the study show the relationship between these variables in terms of the effect of climate on the phenomenon of dust. Because changes in the incidence and frequency of extreme events can have more severe effects and damage than Changes in the average have climatic characteristics and climate change in borderline events show themselves better than changes in the average. In this regard, dust storm days in time Shorter and at least monthly studies with limit events of climatic elements have also been reviewed. In order to monitor the phenomenon of climate change, every year we can update the data and provide new zoning maps of the severity of the phenomenon of climate change in Tehran province and differentiate different regions in terms of vulnerability.

The DSI (Dust Storm Index) method has been used to investigate the frequency and severity of the dust phenomenon (Equation .1). Large-scale use of meteorological records; Which calculates the frequency and intensity of dust storms in the area. This index is a combination of three Local Dust Storm Indexes LDE (Local Dust Storm), MDS( Moderate Dust Storm) and Severe Dust Storm SDS (Sever Dust Storm), based on The number of times the registration of dust phenomenon codes in synoptic stations has been calculated based on the reduction of field of view due to various factors. The values of the above three indices are extracted and calculated based on the reported codes from the location of synoptic stations in the studied areas of Tehran province based on the following definitions.

$$
\mathrm{DSI}=\sum_{i=1}^{n}[(5 \times S D S+M D S+(0.05 \times L D E)] i
$$

Here DSI is Dust Storm Index and calculate method, SDS, is Stormy days with heavy dust, total observations of dust codes, maximum daily code 33-35, MDS, is stormy days with moderate dust, total observations of dust codes maximum daily 30, 32 and 98, and LDE is days with local dust, total observations of dust codes maximum daily 07 and 09

In this research, DSI for different stations in the study period is calculated monthly and annually, and finally the total value of the index for each region is calculated from the total of estimated indices annually. In order to monitor the trend of changes in the study period, it has been statistically analyzed on a monthly and annual basis.

Finally, the mobility of quicksand and climatic variables in sandy areas and sand dunes are investigated to investigate the effect of climate change, especially wind and precipitation on the activity of sands to predict the possibility of hill mobility. The Lancaster method is used in sand dunes and sand dunes and the resulting dust. This method can be predicted for decades to come. The study of the mobility of sand dunes and sandstones in different parts of the world shows different indicators of wind erosion and the mobility of sand dunes they are all based on two factors, which reduce or increase the mobility of sand dunes. The first factor is the degree of wind (W) Which is expressed as the annual percentage of days when the wind speed is higher than the sand threshold speed, and if the degree of wind (W) increases, most sand dunes become mobile. The second factor, on which vegetation growth depends, is expressed as the ratio between the average annual rainfall $(\mathrm{P})$ and the annual potential evaporation (PET) called. The basis of this model is known as the Lancaster Sand Hills Mobility Index (Lancaster, 2013). Based on the developed model of wind erosion,(Chen et al., 2004). 
In this model, the amount of sand mobility (M) is determined from Equation. 2. (M Index calculate method).

$$
\mathrm{M}=\frac{\mathrm{W}}{\left(\frac{P}{P E T}\right)}
$$

In this equation $\mathrm{M}$ is activity of wind sediments, $\mathrm{W}$ is percentage of winds with speeds higher than the erosion threshold speed in $\mathrm{m} / \mathrm{s}$ at a height of $10 \mathrm{~m}$ above the ground, $\mathrm{P}$ is average annual rainfall in $\mathrm{mm}$, and PET shows annual potential evapotranspiration in millimeters.

The experimental value obtained from it is: a. Less than 50 , dormant sand dunes and sand surfaces stabilized by vegetation, b. Between 50-100, active only in sand dune canopy areas; c. Between 100-200, dunes are active, but areas between sand dunes are stabilized by vegetation; And above 200, fully active sand dunes. This index seems to show climatic variables and geomorphic environments in terms of sand activity. After calculating the sand mobility index for different regions of Tehran province, the values obtained are placed in the graph introduced for this purpose to compare their activity index. Finally, in order to investigate the possible effect of climate change on the mobility of quick sands and intensification of dust phenomenon, after calculating the amount of wind sediment activity, using the sensitivity analysis method, the effectiveness of the output variables is determined from the input variables of the model. In other words, sensitivity analysis is a method to change the inputs of a statistical model in an organized (systematic) way that can predict the effects of these changes on the output of the model. The use of sensitivity analysis is used to determine the relationships between model variables with each other and also to prioritize the effect of parameters on the output of the model. Due to this issue and since some climatic elements such as rain, wind and evaporation have a significant effect on the mobility of quick sands, so the desired variables are changed in a reasonable range and the effect of these changes in the output of the model is the amount of sand movement. In this way, the sensitivity of sand mobility to increase or decrease of any of the variables is determined and if the amount of rain decreases or increases in the future or global warming issues lead to more evaporation or decrease or increase of wind. The possible status of these changes is determined. Finally, to express the types of dust phenomena from a meteorological point of view, different scientific names and codes are considered, which are summarized in Table.1.

Table 1. Meteorological code and scientific name of different types of dust phenomenon and its description

\begin{tabular}{|c|c|c|c|c|}
\hline No & Dust code & Dust scientific Name & Dust description & symbol \\
\hline 1 & 05 & Fog, dust & Fog, dust & $\infty$ \\
\hline 2 & 06 & Suspended dust & $\begin{array}{l}\text { Walnuts suspended in the air that came to the station due to sandstorms } \\
\text { outside the station }\end{array}$ & \\
\hline 3 & 07 & Dust & Dust or sand raised by the wind at or near the station during watch time & \\
\hline 4 & 08 & Tornado & Evolved tornadoes in or around the station & 8 \\
\hline 5 & 09 & Storm & Dust storm around watch station & $(s)$ \\
\hline 6 & 30 & Mild or moderate storm & Dust or sand - The intensity of the storm has decreased over the past hour & \\
\hline 7 & 31 & $\begin{array}{l}\text { Dust storm with light } \\
\text { sand }\end{array}$ & $\begin{array}{l}\text { Mild or moderate dust or sand storms have reduced the severity of the storm } \\
\text { over the past hour }\end{array}$ & \\
\hline 8 & 32 & $\begin{array}{l}\text { Dust storm with light } \\
\text { sand }\end{array}$ & $\begin{array}{l}\text { Mild or moderate storms of dust or sand have increased in intensity over the } \\
\text { past hour }\end{array}$ & \\
\hline 9 & 33 & $\begin{array}{l}\text { Dust storm with heavy } \\
\text { sand }\end{array}$ & Severe dust or sand storms - have sharply decreased over the past hour & S) \\
\hline 10 & 34 & $\begin{array}{l}\text { Dust storm with heavy } \\
\text { sand }\end{array}$ & $\begin{array}{l}\text { Severe dust or sandstorm - the intensity of the storm has not changed during } \\
\text { the last hour }\end{array}$ & \\
\hline 11 & 35 & $\begin{array}{l}\text { Dust storm with heavy } \\
\text { sand }\end{array}$ & $\begin{array}{l}\text { Severe dust or sand storm - the intensity of the storm has increased over the } \\
\text { past hour }\end{array}$ & \\
\hline 12 & 98 & $\begin{array}{l}\text { Thunderstorms with } \\
\text { dust }\end{array}$ & Thunderstorms with walnut dust or sandstorms at the time of observation & \\
\hline
\end{tabular}




\section{MEHRABAD STATION TEHRAN}

At Mehrabad station in Tehran, part of the statistics in the period 1990 to 2020 (30-year period) including temperature, humidity, annual rainfall, evapotranspiration and the number of dusty days is prepared, each of which is compared separately in the form of tables and graphs.

It has been compared with the predictable dust storm index (DSI index) and sand dune mobility index (Lancaster index).

\section{TEMPERATURE CHANGES}

Temperature changes in the period 1990 to 2020 (30-year period) in the form of average annual minimum temperature, average annual maximum temperature, average annual temperature as shown in Table.2. According to the statistics collected in the mentioned period, the lowest and highest average minimum annual temperatures were 11.4 and 14.5, respectively, which occurred in 1990 and jointly in 1998 and 2005 , respectively. The lowest and highest average maximum annual temperatures were 21.4 and 24.9 , respectively, which occurred in 1993 and jointly in 1990 and 1993, respectively. The lowest and highest average annual temperatures were 16.3 and 19.3, respectively, which occurred in 1993 and jointly in 1999, 2000 and 1396, respectively. Finally, the statistical changes in temperature are compared graphically and based on the available statistics with the drought and climatic indicators of dust storm (DSI) and mobility of dust and sand fields (Lancaster).

Table 2. Changes in the average minimum and maximum temperatures and the average total temperature in Mehrabad station of Tehran

\begin{tabular}{|c|c|c|c|c|}
\hline No & Year & $\begin{array}{c}\text { Minimum } \\
\text { Temperatures Average }\end{array}$ & $\begin{array}{c}\text { Maximum } \\
\text { Temperatures Average }\end{array}$ & $\begin{array}{c}\text { Temperatures } \\
\text { Average }\end{array}$ \\
\hline 1 & 1991-1990 & 11.4 & 21.8 & 16.7 \\
\hline 2 & 1992-1991 & 12.5 & 21.9 & 16.9 \\
\hline 3 & 1993-1992 & 11.9 & 21.4 & 16.3 \\
\hline 4 & 1994-1993 & 12.9 & 22.7 & 17.5 \\
\hline 5 & 1995-1994 & 12.8 & 23.4 & 18.0 \\
\hline 6 & 1996-1995 & 12.9 & 22.9 & 17.6 \\
\hline 7 & $1997-1996$ & 13.2 & 23.1 & 17.9 \\
\hline 8 & 1998-1997 & 13.4 & 23.4 & 18.0 \\
\hline 9 & 1999-1998 & 14.5 & 24.7 & 19.3 \\
\hline 10 & 2000-1999 & 13.6 & 23.7 & 18.4 \\
\hline 11 & $2001-2000$ & 14.2 & 24.0 & 18.8 \\
\hline 12 & $2002-2001$ & 14.4 & 24.8 & 19.3 \\
\hline 13 & $2003-2002$ & 14.1 & 23.9 & 18.6 \\
\hline 14 & 2004-2003 & 13.7 & 23.8 & 18.5 \\
\hline 15 & $2005-2004$ & 13.5 & 23.2 & 18.0 \\
\hline 16 & $2006-2005$ & 14.5 & 24.2 & 19.0 \\
\hline 17 & $2007-2006$ & 13.9 & 24.2 & 18.6 \\
\hline 18 & $2008-2007$ & 12.9 & 23.3 & 17.7 \\
\hline 19 & 2009-2008 & 14.3 & 24.9 & 19.2 \\
\hline 20 & 2010-2009 & 13.9 & 23.6 & 18.5 \\
\hline 21 & $2011-2010$ & 13.7 & 24.2 & 18.7 \\
\hline 22 & $2012-2011$ & 12.9 & 23.0 & 17.5 \\
\hline 23 & $2013-2012$ & 13.9 & 23.8 & 18.7 \\
\hline 24 & $2014-2013$ & 13.0 & 23.4 & 18.1 \\
\hline 25 & $2015-2014$ & 14.0 & 23.9 & 18.9 \\
\hline 26 & $2016-2015$ & 14.3 & 24.5 & 19.2 \\
\hline 27 & $2017-2016$ & 13.2 & 23.7 & 18.2 \\
\hline 28 & $2018-2017$ & 14.2 & 24.6 & 19.3 \\
\hline 29 & 2019-2018 & 14.1 & 24.0 & 18.9 \\
\hline 30 & $2020-2019$ & 13.6 & 23.7 & 18.5 \\
\hline--- & $* * *$ & 13.50 & 23.6 & 18.30 \\
\hline
\end{tabular}

ISSN: 2231-8186/ @2021 Published by Int. J. Fundam. Phys. Sci 


\section{HUMIDITY CHANGES}

Humidity changes in the period 1990 to 2020 (30-year period) in the form of average annual minimum humidity, average annual maximum humidity, average annual humidity have been studied as Table.3. According to the statistics collected in the mentioned period, the lowest and highest average minimum annual humidity were 20 and 45.1, respectively, which occurred in 1998 and 1991, respectively. The lowest and highest average maximum annual humidity were 46.2 and
77.6, respectively, which occurred in 1990 and 1991, respectively. The lowest and highest average annual humidity were 31.3 and 57.3, respectively, which occurred in 1998 and 2001, respectively.

Finally, the statistical changes of humidity are compared graphically and based on the available statistics with the drought and climatic indicators of dust storm (DSI) and mobility of dust and sand fields (Lancaster).

Table 3. Meteorological data (average minimum and maximum humidity and average total humidity) in Mehrabad station of Tehran

\begin{tabular}{|c|c|c|c|c|}
\hline No & Year & $\begin{array}{c}\text { Minimum } \\
\text { Humidity Average }\end{array}$ & $\begin{array}{c}\text { Maximum } \\
\text { Humidity Average }\end{array}$ & Humidity Average \\
\hline 1 & 1991-1990 & 45.1 & 77.6 & 61.7 \\
\hline 2 & 1992-1991 & 28.4 & 56.8 & 41.3 \\
\hline 3 & 1993-1992 & 28.4 & 56.4 & 41.1 \\
\hline 4 & 1994-1993 & 30.0 & 57.5 & 42.7 \\
\hline 5 & 1995-1994 & 26.8 & 57.4 & 40.9 \\
\hline 6 & 1996-1995 & 30.2 & 57.6 & 43.1 \\
\hline 7 & 1997-1996 & 28.0 & 55.8 & 40.5 \\
\hline 8 & 1998-1997 & 30.5 & 57.6 & 42.8 \\
\hline 9 & 1999-1998 & 26.3 & 54.2 & 39.0 \\
\hline 10 & 2000-1999 & 31.4 & 57.2 & 43.5 \\
\hline 11 & $2001-2000$ & 42.7 & 71.9 & 57.3 \\
\hline 12 & $2002-2001$ & 27.3 & 55.3 & 40.0 \\
\hline 13 & $2003-2002$ & 26.6 & 54.0 & 39.2 \\
\hline 14 & $2004-2003$ & 28.1 & 55.3 & 40.5 \\
\hline 15 & $2005-2004$ & 30.5 & 58.9 & 43.7 \\
\hline 16 & 2006-2005 & 25.9 & 53.1 & 38.2 \\
\hline 17 & $2007-2006$ & 29.9 & 57.7 & 42.7 \\
\hline 18 & $2008-2007$ & 28.5 & 56.9 & 41.6 \\
\hline 19 & 2009-2008 & 20.2 & 46.2 & 31.6 \\
\hline 20 & $2010-2009$ & 23.8 & 53.1 & 36.8 \\
\hline 21 & $2011-2010$ & 21.4 & 49.2 & 33.6 \\
\hline 22 & $2012-2011$ & 24.0 & 51.6 & 36.1 \\
\hline 23 & 2013-2012 & 23.0 & 50.4 & 35.1 \\
\hline 24 & 2014-2013 & 21.5 & 49.5 & 34.0 \\
\hline 25 & $2015-2014$ & 21.2 & 48.7 & 33.1 \\
\hline 26 & $2016-2015$ & 21.6 & 47.6 & 33.2 \\
\hline 27 & 2017-2016 & 21.2 & 49.6 & 33.7 \\
\hline 28 & 2018-2017 & 20.0 & 46.2 & 31.3 \\
\hline 29 & 2019-2018 & 23.6 & 50.5 & 35.7 \\
\hline 30 & 2020-2019 & 24.2 & 52.5 & 36.8 \\
\hline --- & $* * *$ & 26.50 & 54.20 & 39.10 \\
\hline
\end{tabular}

ISSN: 2231-8186/ @2021 Published by Int. J. Fundam. Phys. Sci 
CHANGES IN RAINFALL, ANNUAL EVAPORATION, NUMBER OF DUST DAYS IN YEAR

Changes in rainfall, annual evaporation, number of dust days in the period 1990 to 2020 (30-year period) have been studied as Table.4. According to the statistics collected in the mentioned period, the lowest and highest average rainfall was 111.6 and 374, respectively, which occurred in 2014 and 2020, respectively. The lowest and highest average annual evaporation were 1618.4 and 2641.8, respectively, which occurred in 2009 and 2012, respectively. The minimum and maximum number of annual dust days were 4 days and 56 days, respectively, which occurred in 1998 and 2009, respectively. Finally, the statistical changes of precipitation, evaporation, number of dust days were compared graphically and based on available statistics with drought and climatic indicators of dust storm (DSI) and mobility of dust and sand fields (Lancaster). A brief look shows that on days with heavy dust, the values of temperature, very high evaporation and humidity, rainfall was very low, which shows the significant impact of climatic factors on the phenomenon of fine dust, which is one of the main objectives of the project. Is present.

Table.4. Meteorological data (rainfall and evaporation, number of annual dust days) at Mehrabad station in Tehran

\begin{tabular}{|c|c|c|c|c|}
\hline No & Year & Annual Rainfall & Annual Evaporation & Dust Days \\
\hline 1 & 1991-1990 & 122.6 & 1927.0 & 0 \\
\hline 2 & $1992-1991$ & 267.2 & 2063.0 & 35 \\
\hline 3 & 1993-1992 & 319.8 & 1827.0 & 15 \\
\hline 4 & 1994-1993 & 218.3 & 2072.6 & 23 \\
\hline 5 & 1995-1994 & 254.1 & 2063.3 & 41 \\
\hline 6 & 1996-1995 & 319.4 & 2191.2 & 10 \\
\hline 7 & 1997-1996 & 154.4 & 2644.4 & 13 \\
\hline 8 & 1998-1997 & 236.5 & 2672.1 & 11 \\
\hline 9 & 1999-1998 & 182.8 & 2641.3 & 4 \\
\hline 10 & 2000-1999 & 168.4 & 2495.8 & 29 \\
\hline 11 & $2001-2000$ & 179.6 & 2531.4 & 53 \\
\hline 12 & $2002-2001$ & 191.9 & 2623.2 & 36 \\
\hline 13 & $2003-2002$ & 333.4 & 2366.9 & 18 \\
\hline 14 & $2004-2003$ & 315.7 & 2030.2 & 31 \\
\hline 15 & $2005-2004$ & 329.1 & 2040.2 & 12 \\
\hline 16 & $2006-2005$ & 270.9 & 1989.7 & 17 \\
\hline 17 & $2007-2006$ & 232.6 & 2176.8 & 15 \\
\hline 18 & $2008-2007$ & 293.4 & 2333.1 & 19 \\
\hline 19 & $2009-2008$ & 138.3 & 2396.9 & 44 \\
\hline 20 & 2010-2009 & 235.4 & 1618.4 & 56 \\
\hline 21 & 2011-2010 & 217.1 & 2308.2 & 33 \\
\hline 22 & $2012-2011$ & 318.0 & 2343.6 & 54 \\
\hline 23 & $2013-2012$ & 242.0 & 2641.8 & 29 \\
\hline 24 & $2014-2013$ & 111.6 & 2635.6 & 26 \\
\hline 25 & $2015-2014$ & 136.5 & 2513.7 & 22 \\
\hline 26 & $2016-2015$ & 202.4 & 2508.1 & 40 \\
\hline 27 & $2017-2016$ & 168.0 & 2540.1 & 25 \\
\hline 28 & $2018-2017$ & 152.7 & 2474.9 & 17 \\
\hline 29 & $2019-2018$ & 256.0 & 2379.0 & 12 \\
\hline 30 & $2020-2019$ & 374.0 & 2318.4 & 8 \\
\hline--- & $* * *$ & $7080.60=236.02$ & $66326.60=2368.80$ & $=75225.06$ \\
\hline
\end{tabular}


COMPARISON OF CHANGES IN TEMPERATURE, HUMIDITY, RAINFALL, ANNUAL EVAPORATION, NUMBER OF DAYS AND DUST PER YEAR

As in separate sections, changes in temperature, humidity, precipitation, evaporation and the number of days of dust per year in the statistical period from 1990 to 2019 (30-year period) have been studied, in this section all the mentioned factors in the form of a table (Table.5) Compared centrally. According to the mentioned table in 1991, 1993, 2000, 2001, 2003, 2008, 2009, 2010, 2011, 2015, the number of dust days per year was high (above 30 days per year) which is compared with the factors of temperature, humidity, rainfall, Evaporation shows that in the mentioned years, the amount of precipitation, low humidity and, conversely, the amount of temperature, evaporation shows an almost high number, which indicates the acceptable accuracy of meteorological data at Mehrabad station and the realization of one of the important goals of the present project. That is, the impact of climatic factors on the unexpected incident of fine dust and dust in the region, all cases separately in the form of graphs and based on available statistics with dust and climate indicators of dust storm (DSI) and mobility of dust and sand fields (Lancaster) has been compared.

Table.5. Comparison of temperature, humidity, rainfall, evaporation, number of dusty days average in Mehrabad station of Tehran

\begin{tabular}{|c|c|c|c|c|c|c|}
\hline No & Year & Temperature.Av & Humidity.Av & Rainfall.Av & Evaporation.Av & Dust.Av \\
\hline 1 & 1991-1990 & 16.7 & 61.7 & 122.6 & 1927.0 & 0 \\
\hline 2 & $1992-1991$ & 16.9 & 41.3 & 267.2 & 2063.0 & 35 \\
\hline 3 & 1993-1992 & 16.3 & 41.1 & 319.8 & 1827.0 & 15 \\
\hline 4 & 1994-1993 & 17.5 & 42.7 & 218.3 & 2072.6 & 23 \\
\hline 5 & $1995-1994$ & 18.0 & 40.9 & 254.1 & 2063.3 & 41 \\
\hline 6 & $1996-1995$ & 17.6 & 43.1 & 319.4 & 2191.2 & 10 \\
\hline 7 & $1997-1996$ & 17.9 & 40.5 & 154.4 & 2644.4 & 13 \\
\hline 8 & $1998-1997$ & 18.0 & 42.8 & 236.5 & 2672.1 & 11 \\
\hline 9 & 1999-1998 & 19.3 & 39.0 & 182.8 & 2641.3 & 4 \\
\hline 10 & 2000-1999 & 18.4 & 43.5 & 168.4 & 2495.8 & 29 \\
\hline 11 & $2001-2000$ & 18.8 & 57.3 & 179.6 & 2531.4 & 53 \\
\hline 12 & $2002-2001$ & 19.3 & 40.0 & 191.9 & 2623.2 & 36 \\
\hline 13 & 2003-2002 & 18.6 & 39.2 & 333.4 & 2366.9 & 18 \\
\hline 14 & $2004-2003$ & 18.5 & 40.5 & 315.7 & 2030.2 & 31 \\
\hline 15 & $2005-2004$ & 18.0 & 43.7 & 329.1 & 2040.2 & 12 \\
\hline 16 & $2006-2005$ & 19.0 & 38.2 & 270.9 & 1989.7 & 17 \\
\hline 17 & $2007-2006$ & 18.6 & 42.7 & 232.6 & 2176.8 & 15 \\
\hline 18 & $2008-2007$ & 17.7 & 41.6 & 293.4 & 2333.1 & 19 \\
\hline 19 & $2009-2008$ & 19.2 & 31.6 & 138.3 & 2396.9 & 44 \\
\hline 20 & 2010-2009 & 18.5 & 36.8 & 235.4 & 1618.4 & 56 \\
\hline 21 & $2011-2010$ & 18.7 & 33.6 & 217.1 & 2308.2 & 33 \\
\hline 22 & $2012-2011$ & 17.5 & 36.1 & 318.0 & 2343.6 & 54 \\
\hline 23 & 2013-2012 & 18.7 & 35.1 & 242.0 & 2641.8 & 29 \\
\hline 24 & 2014-2013 & 18.1 & 34.0 & 111.6 & 2635.6 & 26 \\
\hline 25 & $2015-2014$ & 18.9 & 33.1 & 136.5 & 2513.7 & 22 \\
\hline 26 & $2016-2015$ & 19.2 & 33.2 & 202.4 & 2508.1 & 40 \\
\hline 27 & $2017-2016$ & 18.2 & 33.7 & 168.0 & 2540.1 & 25 \\
\hline 28 & $2018-2017$ & 19.3 & 31.3 & 152.7 & 2474.9 & 17 \\
\hline 29 & 2019-2018 & 18.9 & 35.7 & 256.0 & 2379.0 & 12 \\
\hline 30 & 2020-2019 & 18.5 & 36.8 & 374.0 & 2318.4 & 8 \\
\hline--- & $* * *$ & 18.30 & 39.10 & $7080.60=236.02$ & $66326.60=2368.80$ & $=75225.06$ \\
\hline
\end{tabular}

ISSN: 2231-8186/ @2021 Published by Int. J. Fundam. Phys. Sci 


\section{COMPARISON OF DSI AND LANCASTER INDEX CHANGES BASED ON AVAILABLE DATA \\ E.1.DSI Index}

Through equation.1, for years with data in Mehrabad station of Tehran, the values of dust storm index were examined in the form of table. 6 and displayed in the form of graph.1. The above table and graph.1 show that in the years 1993, 1996,
2000, 2001, 2002, 2003, 2005, 2017, 2010, 2015, 2017, the dust storm index (DSI index) is almost too high and above the number One shows that in most of the mentioned years, the values of temperature and evaporation are high and the values of precipitation and humidity are relatively low, which shows the direct relationship between the dust storm index (DSI index) and the factors and data. The weather is in Mehrabad station of Tehran.

Table.6. DSI index values and its mean during the statistical period in Mehrabad station of Tehran

\begin{tabular}{|c|c|c|c|}
\hline No & Year & Dsi amount & Dsi average \\
\hline 1 & 1991-1990 & $0 / 4$ & $0 / 93$ \\
\hline 2 & 1992-1991 & $0 / 3$ & $0 / 93$ \\
\hline 3 & 1993-1992 & $1 / 65$ & $0 / 93$ \\
\hline 4 & 1994-1993 & $0 / 45$ & $0 / 93$ \\
\hline 5 & 1995-1994 & $0 / 45$ & $0 / 93$ \\
\hline 6 & 1996-1995 & $0 / 9$ & $0 / 93$ \\
\hline 7 & 1997-1996 & $1 / 35$ & $0 / 93$ \\
\hline 8 & 1998-1997 & $0 / 5$ & $0 / 93$ \\
\hline 9 & 1999-1998 & $0 / 85$ & $0 / 93$ \\
\hline 10 & 2000-1999 & $1 / 05$ & $0 / 93$ \\
\hline 11 & $2001-2000$ & $1 / 2$ & $0 / 93$ \\
\hline 12 & $2002-2001$ & $1 / 75$ & $0 / 93$ \\
\hline 13 & $2003-2002$ & $1 / 1$ & $0 / 93$ \\
\hline 14 & 2004-2003 & $0 / 75$ & $0 / 93$ \\
\hline 15 & $2005-2004$ & $0 / 85$ & $0 / 93$ \\
\hline 16 & $2006-2005$ & $1 / 1$ & $0 / 93$ \\
\hline 17 & $2007-2006$ & $1 / 2$ & $0 / 93$ \\
\hline 18 & $2008-2007$ & $0 / 15$ & $0 / 93$ \\
\hline 19 & 2009-2008 & $0 / 3$ & $0 / 93$ \\
\hline 20 & 2010-2009 & $0 / 15$ & $0 / 93$ \\
\hline 21 & $2011-2010$ & $0 / 85$ & $0 / 93$ \\
\hline 22 & $2012-2011$ & $1 / 55$ & $0 / 93$ \\
\hline 23 & $2013-2012$ & $2 / 15$ & $0 / 93$ \\
\hline 24 & 2014-2013 & $2 / 3$ & $0 / 93$ \\
\hline 25 & 2015-2014 & $0 / 75$ & $0 / 93$ \\
\hline 26 & 2016-2015 & $0 / 50$ & $0 / 93$ \\
\hline 27 & 2017-2016 & $0 / 55$ & $0 / 93$ \\
\hline 28 & $2018-2017$ & --- & --- \\
\hline 29 & 2019-2018 & --- & --- \\
\hline 30 & 2020-2019 & --- & --- \\
\hline --- & $* * *$ & --- & --- \\
\hline
\end{tabular}




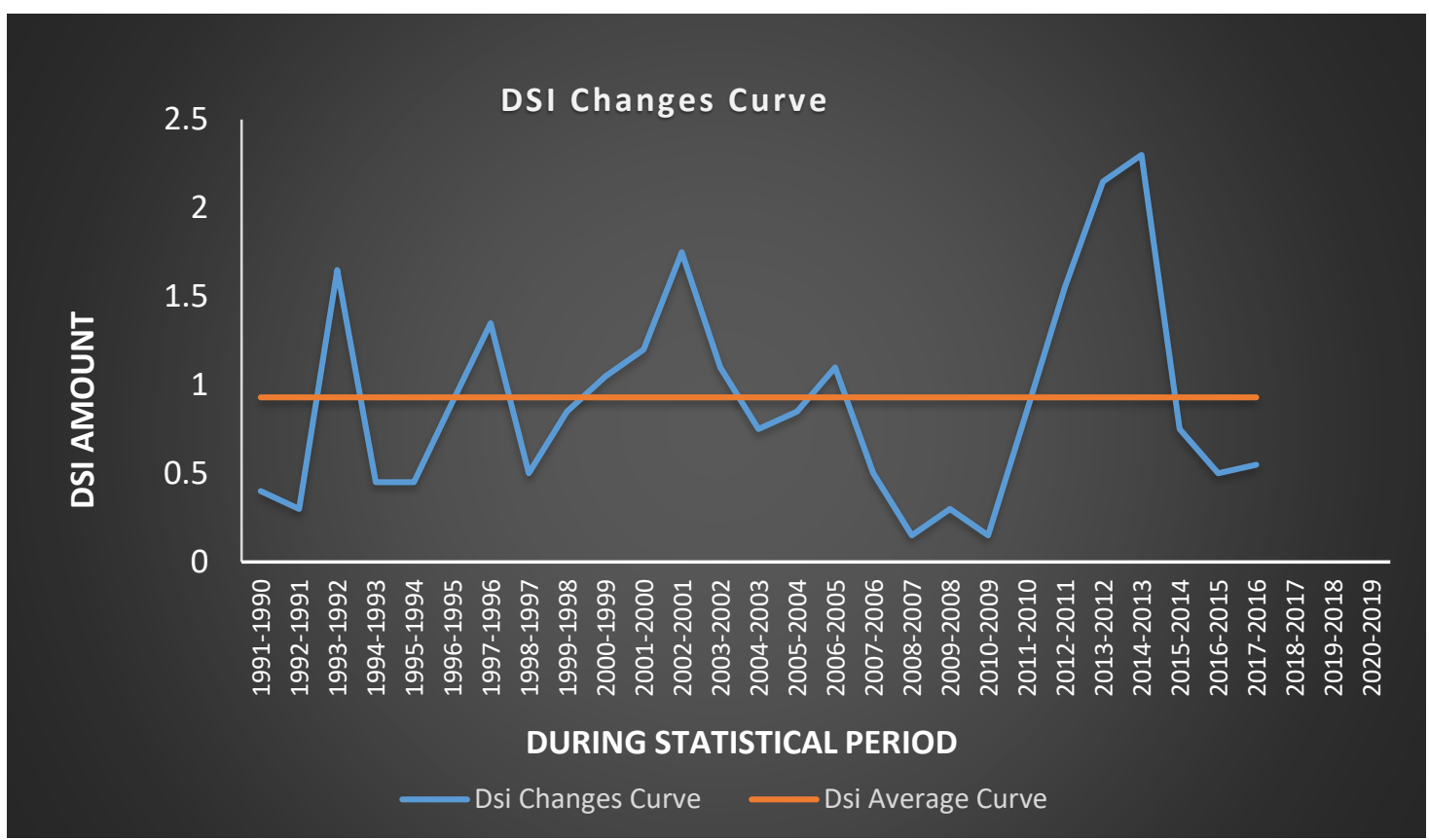

Figure 1. Dust storm change curve (DSI index) during the statistical period of Mehrabad station

\section{LANCASTER INDEX}

Using Equation.2 for the years with statistics in Mehrabad station of Tehran, the values of sand damp mobility index (Lancaster index) were examined in the form of table number.7 and displayed as graph.2 The mentioned table and graph.2 show that in the years 1990, 1995, 1998, 2000, 2001, 2002, 2003, 2010, 2011, 2012, 2013,2014, 2015, 2016, 2017 sand hills mobility index (Lancaster Index) is almost as high as 50. It is noteworthy that in most of these years the values of temperature and evaporation are high and the values of precipitation and humidity are relatively low, which indicates a direct relationship between the hill mobility index. Sand dunes (Lancaster index) with weather and meteorological data at Mehrabad station in Tehran.

Table 7. Lancaster index values and its average during the statistical period at Mehrabad station in Tehran

\begin{tabular}{cccc}
\hline No & year & Lancaster amount & Lancaster average \\
\hline 1 & $1991-1990$ & $76 / 39$ & $59 / 30$ \\
2 & $1992-1991$ & $39 / 61$ & $59 / 30$ \\
3 & $1993-1992$ & $40 / 38$ & $59 / 30$ \\
4 & $1994-1993$ & $42 / 76$ & $59 / 30$ \\
5 & $1995-1994$ & $38 / 49$ & $59 / 30$ \\
6 & $1996-1995$ & $77 / 92$ & $59 / 30$ \\
7 & $1997-1996$ & $27 / 08$ & $59 / 30$ \\
8 & $1998-1997$ & $83 / 74$ & $59 / 30$ \\
9 & $1999-1998$ & $39 / 50$ & $59 / 30$ \\
10 & $2000-1999$ & $67 / 55$ & $59 / 30$ \\
11 & $2001-2000$ & $63 / 21$ & $59 / 30$ \\
12 & $2002-2001$ & $69 / 22$ & $59 / 30$ \\
13 & $2003-2002$ & $50 / 63$ & $59 / 30$ \\
14 & $2004-2003$ & $43 / 22$ & $59 / 30$ \\
15 & $2005-2004$ & $40 / 34$ & $59 / 30$ \\
16 & $2006-2005$ & $47 / 56$ & $59 / 30$
\end{tabular}




\begin{tabular}{lccc}
17 & $2007-2006$ & $47 / 57$ & $59 / 30$ \\
18 & $2008-2007$ & $36 / 01$ & $59 / 30$ \\
19 & $2009-2008$ & $84 / 04$ & $59 / 30$ \\
20 & $2010-2009$ & $60 / 81$ & $59 / 30$ \\
21 & $2011-2010$ & $67 / 30$ & $59 / 30$ \\
22 & $2012-2011$ & $33 / 37$ & $59 / 30$ \\
23 & $2013-2012$ & $49 / 55$ & $59 / 30$ \\
24 & $2014-2013$ & $82 / 38$ & $59 / 30$ \\
25 & $2015-2014$ & $127 / 35$ & $59 / 30$ \\
26 & $2016-2015$ & $67 / 39$ & $59 / 30$ \\
27 & $2017-2016$ & $97 / 85$ & $59 / 30$ \\
28 & $2018-2017$ & - & - \\
29 & $2019-2018$ & - & - \\
30 & $2020-2019$ & - & - \\
\hline
\end{tabular}

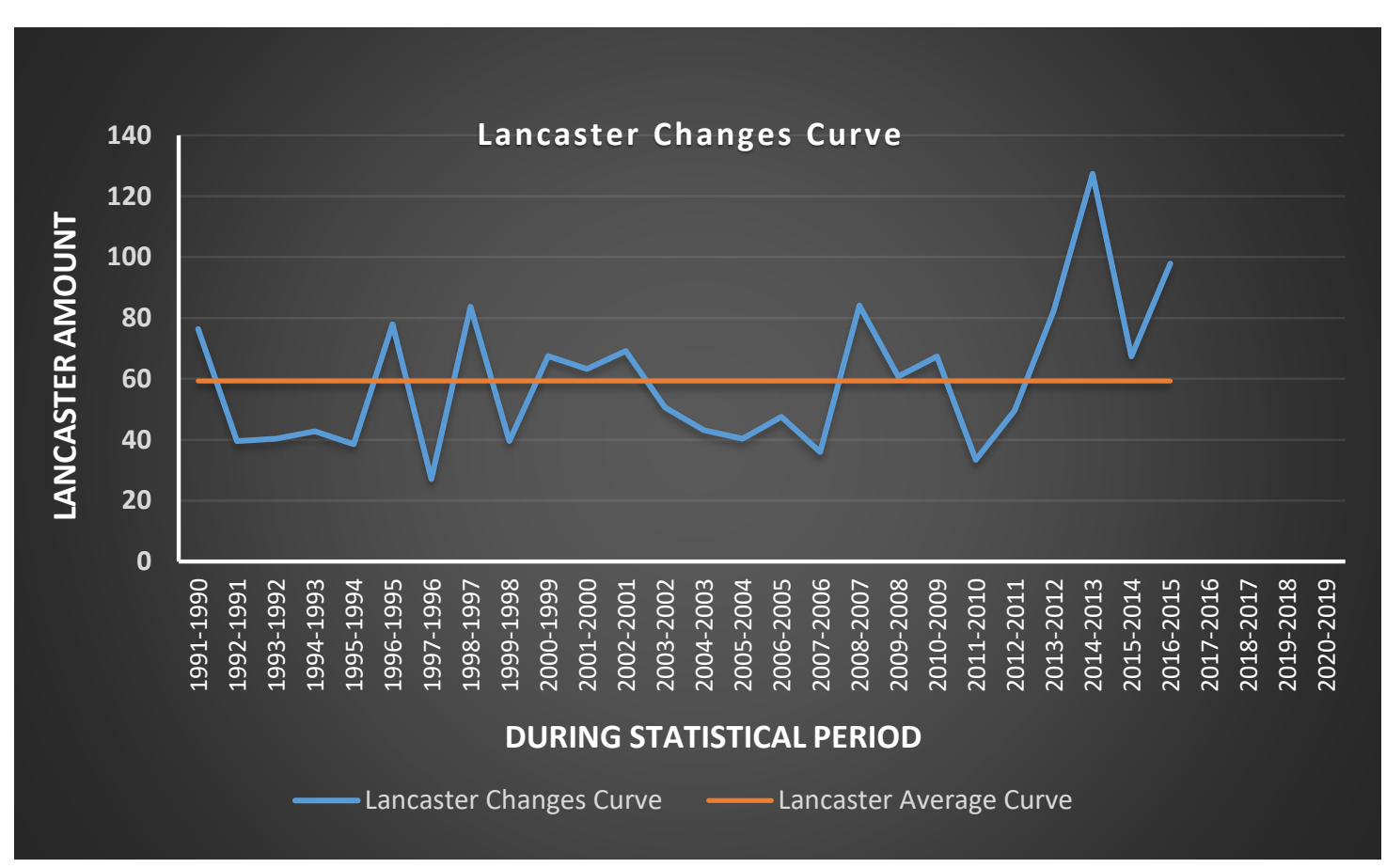

Figure 2. changes of sand dunes mobility curve (Lancaster index) during the statistical period of Mehrabad station

\section{DISCUSSION}

As mentioned, various activities have been carried out in the world regarding the origin, nature, characteristics, routes of movement, existing compositions of dust storms and dust particles, effects and consequences of their spread over cities and villages. Dust source areas in the world usually have an annual rainfall of less than 288 to $258 \mathrm{~mm}$ and are located topically in the lowlands. Among the most active sources of dust production in the world can be found in deserts and dry lakes that he pointed out that the cause of regional climate change has turned into small deserts. Dust is one of the most important environmental problems in the world that has attracted a lot of attention in recent years. This problem affects all aspects of human daily life (such as human health, the impact on the electricity distribution industry, the development of desertification, agriculture and ecotourism, etc.). For sustainable management of dust or fine dust, it should be first addressed and then comprehensive management should be considered. Internal or external source of dust or fine dust is important because it will consider the need to invest in the region or outside the region, and comprehensive management is emphasized because if not all aspects are considered. Sustainable management will not be achieved that affects the source of dust or fine dust, and as a result, all actions taken will be ineffective. Multilateral solutions and while examining the 
ecosystem from various aspects such as soil science, geology and climatology in this view have been considered by researchers. As mentioned, the storms in the Middle East are mainly divided into different types of northern, frontal and convective.

The main type of these storms is the northern type, which occurs in Iraq, Kuwait and the Arabian Peninsula. In recent years, dust storms in the Middle East, especially in the deserts of Saudi Arabia and Iraq, have had many harmful effects on our country, extending to major cities. Analysis of currents and satellite imagery studies in the Middle East show that the world's sandy desert called "Rabi al-Khali", due to its lack of vegetation and recent droughts, is one of the sources of dust in the eastern part of the Middle East. Oman and the United Arab Emirates.

In general, researchers have listed the most important foreign sources of dust or fine dust penetrating into Iran as follows: three centers in Syria, one center on the Syrian-Iraqi border, four centers in northern Iraq and the Euphrates River basin, and one center in central Iraq. Other sources point to the eastern and southeastern plains of Saudi Arabia, parts of the United Arab Emirates, Yemen, and Kuwait, as well as North Africa, as foreign sources of dust in Iran. Together, these sources cause dust storms known as Arabian dust mites.

Discussion and Analysis In studies that examined the incidence of dust or dust in the southwestern region of Iran over a 10-year period from 1998 to 2007 in 10 different cities, the researchers observed that in this 10-year period, a total of cities. There were 4552 days of dust in the study that the source of dust or fine dust in 3285 days (72\%) were deserts of neighboring countries of Khuzestan province such as Iraq, Syria and Saudi Arabia and only in 1264 cases (28\%), the source of this dust or The dust was in Khuzestan province itself, which, according to researchers, is dry and devoid of vegetation in a large part of the Khuzestan plain, especially in its central areas.

However, despite the fact that experts have mentioned the share of foreign centers in the production of dust more than $70 \%$, the results of research show that there are several areas inside our country that are able to play a role in the production of dust storms. Have. Among these, dried wetlands such as Hur al-Azim or Hur al-Hawizeh wetland, which is one of the most important centers of dust, are mentioned. However, only one third of the Hur al-Azim wetland is located in our country and the other two thirds are in Iraq. Also, in some sources, the Abadan Delta and its sand dunes are mentioned as areas prone to dust or dust mites.

Discussion and analysis in another comprehensive study conducted by our country's researchers to identify dust hotspots, using a combined study of meteorological and satellite data, days with dust or fine dust along with horizontal visibility of synoptic stations in Khuzestan and Ilam provinces in A relatively long period from 1990 to 2013 has been studied. The result of this study was the identification of 62 different points as the internal source of dust or fine dust, which were classified in three general areas: Zone 1 located in the west of Ilam and the border of this province with Iraq, Zone 2 including southern Ilam, north of Khuzestan and their intersection with The Iraqi border and finally Zone 3, which includes the areas around Hur al-Azim Wetland. According to the results of this research, dust or fine dust created from region 1 often does not enter the territory of our country. However, regions 2 and 3 are the main causes of dust or fine dust in Khuzestan province, the first of which completely affects the north, north of Khuzestan and the other west and southwest of this province.

But Tehran province (along with Alborz province) about 74,000 hectares of land in the south, southwest and east of Tehran province are prone to dust, which from this area according to the characteristics and conditions and soil location of the area around Varamin city (to Special area of Charmshahr) and Rey city (southeastern and western areas of Rey) is more than other cities of the province, in general, most of the area around Garmsar-Qom highway (especially in the southern areas of the road) in areas of Tehran province with the center Dust or fine dust is associated (Director General of Environment of Tehran Province), in Tehran Province, uncontrolled extraction of groundwater and sand mines, development of water-based industries (such as steel), increasing the level of water evaporation (with the construction of dams), etc. are among the factors that They have created dust source on the outside of cities in Tehran province.

\section{CONCLUSION}

As mentioned, Tehran is prone to dust in the lands south, southwest and east, which from this area according to the characteristics and conditions and soil position of the area around Varamin city (especially Charmshahr area) and Rey city (areas). Southeast and west of Rey) has been more than other cities in the province. However, in Tehran province, uncontrolled extraction of groundwater and sand mines, development of water-based industries (such as steel), increasing the level of water evaporation (with the construction of dams), etc. are among the factors that cause dust source. They are also on the outside of cities in Tehran province.

However, in order to study the climatic factors affecting the phenomenon of dust and fine dust, in the beginning, Mehrabad station was collected and studied and analysis for the preparation of preliminary meteorological data. The results showed that in this station in terms of temperature in 1993 the lowest value and in 1998, 1380, 1396 the highest value and in terms of humidity in 2015 the lowest amount of humidity and in 2001 the highest amount of humidity and in terms of rainfall in 2013 .

The lowest amount of precipitation and in 2017 the highest amount of precipitation and in terms of evaporation in 2010 the lowest amount of evaporation and in 2013 the highest amount of evaporation and finally in terms of number of dust days in 1998 the lowest number of days and in 2009 the highest number of round days And the dust has been recorded. The important result is that in Mehrabad station, dust storm drought indices (DSI index) in the years 1994, 1997, 2010, 2011, 2012, 2013, 2014, 2015, 2016, 2017 show almost a high number and above number one. 
It is noteworthy that in most of the mentioned years, the values of temperature and evaporation are high and the values of precipitation and humidity are relatively low, which shows the direct relationship between the dust storm index (DSI index) and meteorological factors and data at the station.

Mehrabad is Tehran. Also in the years 1990, 1994, 1997, 2010, 2011, 2012, 2013, 2014, 2015, 2016, 2017, 2018 the mobility index of sand dunes (Lancaster index) is almost too high and above the number It is noteworthy that in most of the mentioned years, the values of temperature and evaporation are high and the values of precipitation and humidity are relatively low, which shows the direct relationship between the mobility index of sand dunes (Lancaster index) and Meteorological factors and data are in Mehrabad station of Tehran.

\section{REFERENCES}

Chen, Y.-S., Sheen, P.-C., Chen, E.-R., Liu, Y.-K., Wu, T.-N., \& Yang, C.-Y. J. E. r. (2004). Effects of Asian dust storm events on daily mortality in Taipei, Taiwan. 95(2), 151-155.

Clarke, M. L., \& Rendell, H. M. J. J. o. A. E. (1998). Climate change impacts on sand supply and the formation of desert sand dunes in the south-west USA. 39(3), 517-531.

Esmaeili.O. (2005). Preliminary mapping of the main centers dust generation by GIS, Sharif University of Technology. Sharif University of Technology.

Furman, H. K. H. J. I., \& Environment, B. (2003). Dust storms in the Middle East: sources of origin and their temporal characteristics. 12(6), 419-426.

Kermani, T., Izanlo. (2010). Dust storms assessment as an environmental crisis and its impact on human health.

Lancaster, N. (2013). 13.9 Climate Change and Aeolian Processes.

Lashkari, H., \& Keykhosravi, G. (2008). Statistical synoptic analysis of dust storm in khorasan razavi province (19932005).

\section{ACKNOWLEDGMENT}

The present article is the result of the research project " Monitoring of Climatic Factors Affecting on Dust \& Sand Storm in Tehran Province with the code 0-09-09-127-961047 "which is necessary from the esteemed officials of Agricultural and Natural Resources Research and Education Center of Tehran Province and subsequently the officials and staff of the Research Institute of Forests and Raneland of the country who helped to provide the necessary conditions for review, approval and implementation as well as the preparation of this report, and also my colleagues in the Soil Conservation and Watershed Management Department Mr. Aziz Darvishi, Engineer I sincerely thank Samaneh Abdousi, Engineer and Engineer Bahram Farshadpour who have played a useful and effective role in data collection, sampling, and map processing.

Liu, J.-T., Jiang, X.-G., Zheng, X.-J., Kang, L., \& Qi, F.-Y. J. T. (2004). An intensive Mongolian cyclone genesis induced severe dust storm. 15(5), 1019-1033.

Natsagdorj, L., Jugder, D., \& Chung, Y. J. A. E. (2003). Analysis of dust storms observed in Mongolia during 1937-1999. 37(9-10), 1401-1411.

Pelletier, J. D., Brad Murray, A., Pierce, J. L., Bierman, P. R., Breshears, D. D., Crosby, B. T., . . Houser, C. J. E. s. F. (2015). Forecasting the response of Earth's surface to future climatic and land use changes: A review of methods and research needs. 3(7), 220-251.

Prospero, J. M., Blades, E., Mathison, G., \& Naidu, R. J. A. (2005). Interhemispheric transport of viable fungi and bacteria from Africa to the Caribbean with soil dust. 21(1), 1-19.

Prospero, J. M., \& Lamb, P. J. J. S. (2003). African droughts and dust transport to the Caribbean: Climate change implications. 302(5647), 1024-1027.

Rezaeei.M. (2014). The effects of dust storms on human life and the environment, . The Environmental Magazine.

Sweeney, M. R., McDonald, E. V., \& Etyemezian, V. J. G. (2011). Quantifying dust emissions from desert landforms, eastern Mojave Desert, USA. 135(1-2), 21-34. 